حكمرانى آب در حوزه آبخيز سفيدرود بزرَى با استفاده از رويكرد تئورى بازىها

\author{
محمدر رضا مر تضى بور '، على شاهنظرى 'و محمدر ضا خالديان'

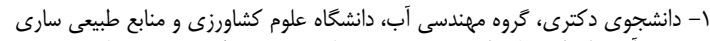

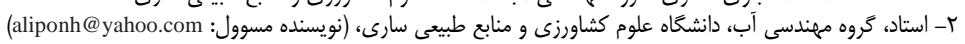

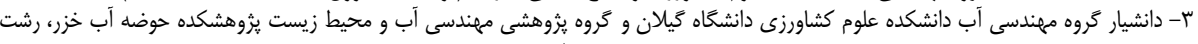

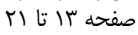

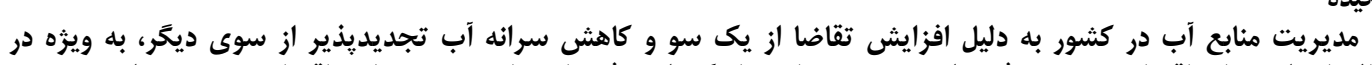

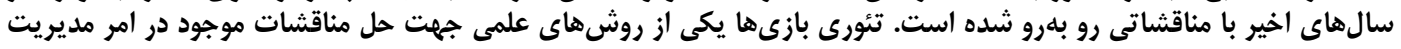

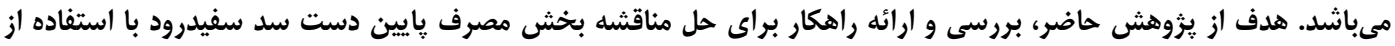

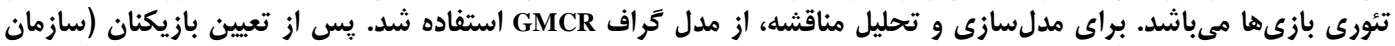

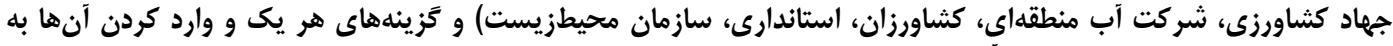

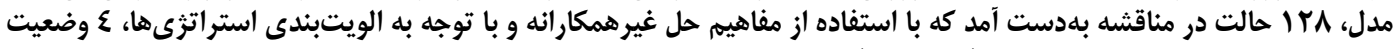

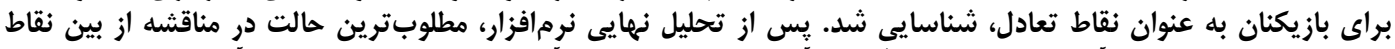

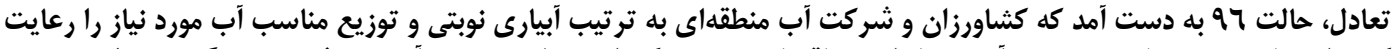

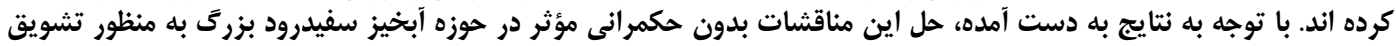

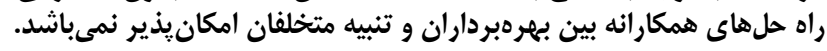

وازههاى كليدى: تئورى بازىها، مناقشه، نقاط تعادل، مدل GMCR، حوزه آبخيز سفيدرود

اين تنشها كم و بيش در ساير حوزههاى آبخيز كشور از آبخديز

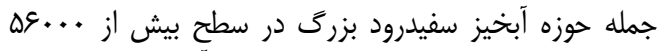

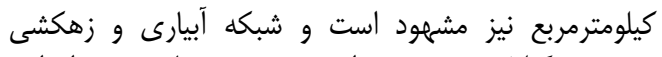

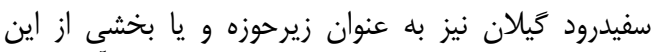

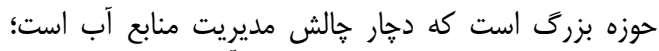

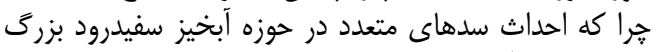

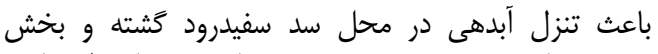

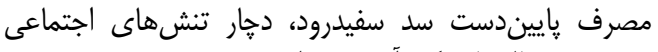
بلويزه در سال هاى كم آبى شده است.

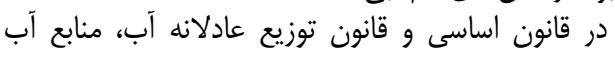

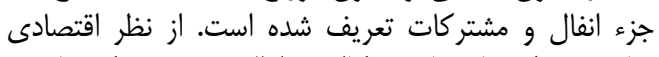

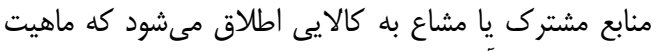

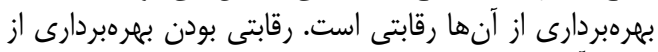

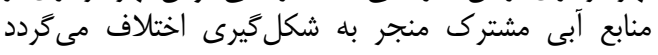

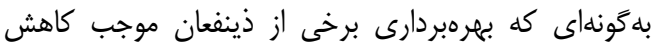

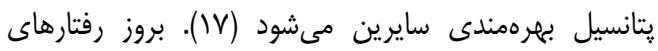

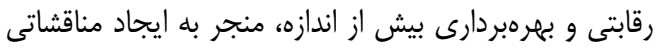

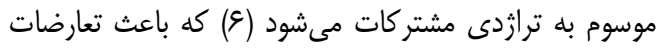

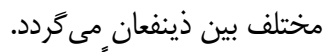

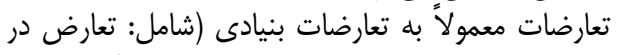

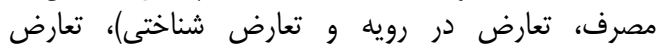

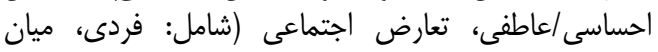

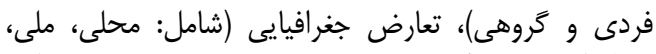

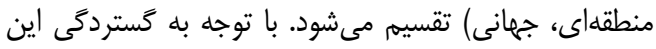

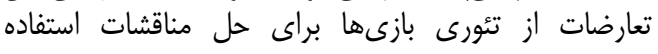
مىشود.
مقدمه

حكمرانى آب به طيف وسيعى از نظامهاى سياسى،

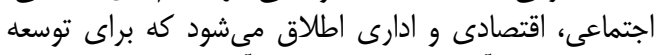

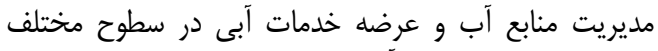

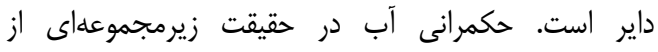

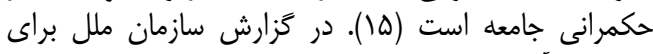

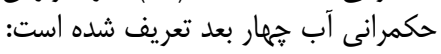

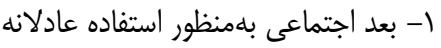

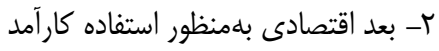

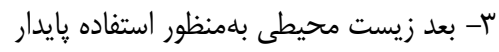

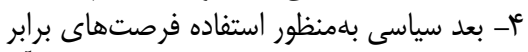

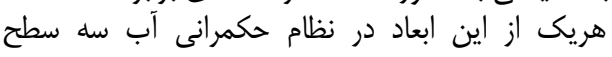

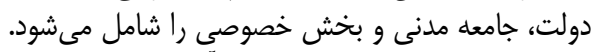

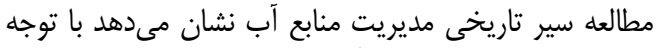

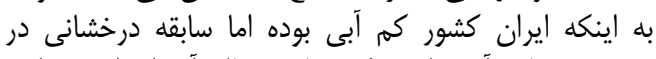

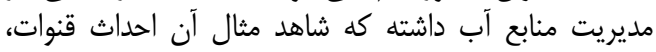

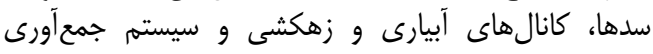

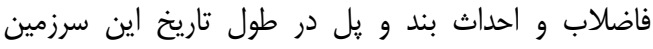

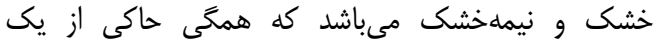

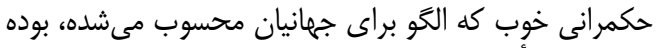

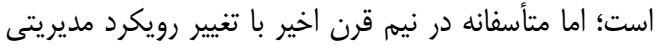

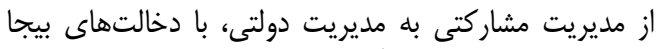

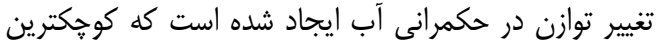

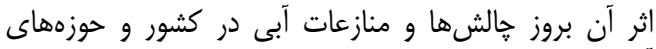

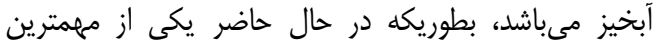
اختلافات و مناقشات آبى در حوزه آبخيز درا زاضئ زايندهرود مشاهده

مىشود (ه). 
حاكميتى كه از طريق تشويق راهحل همكارانه بين ذينفعان و و

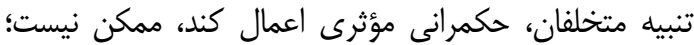

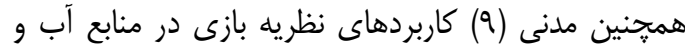
مزاياى آن را بررسى كرده است.

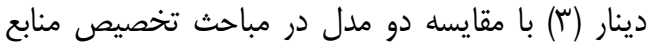

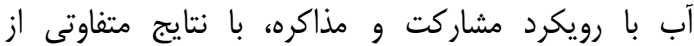

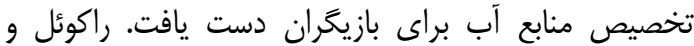

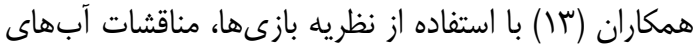

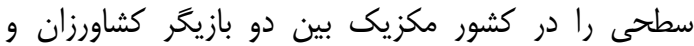

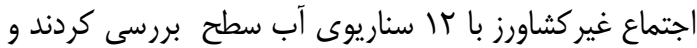

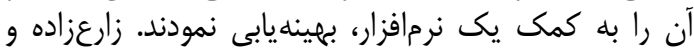

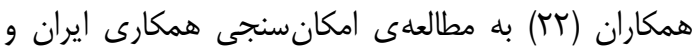

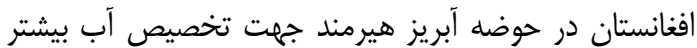

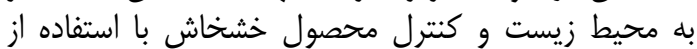

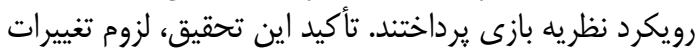

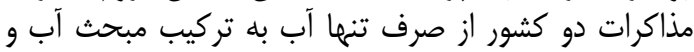

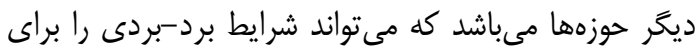

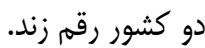

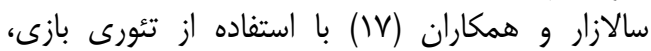

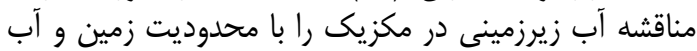

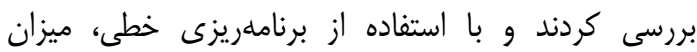

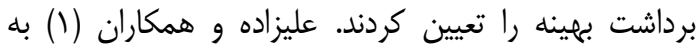

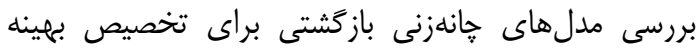

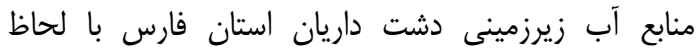

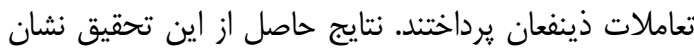

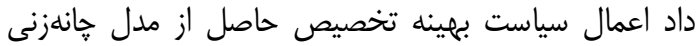

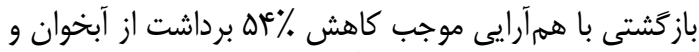

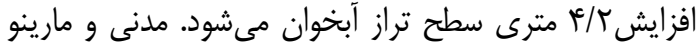

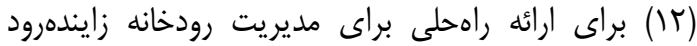

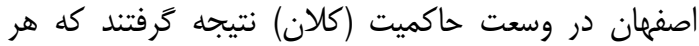

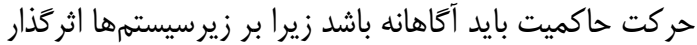

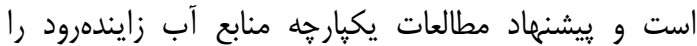

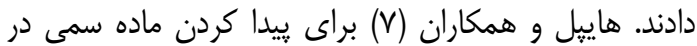

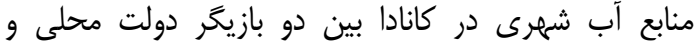

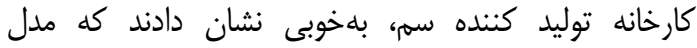
GMCR

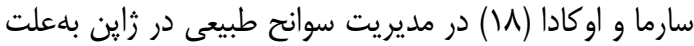

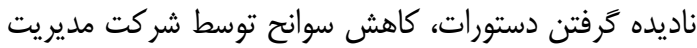

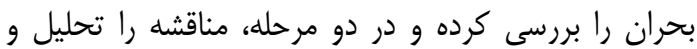
نقطه تعادل مناقشه را براى برقرار درى درد ارتباط مؤثر بين آنها

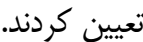

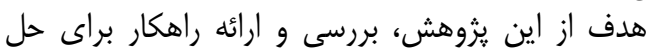

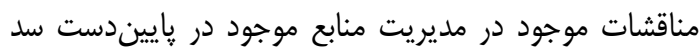

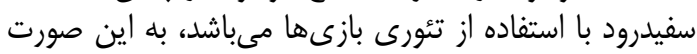

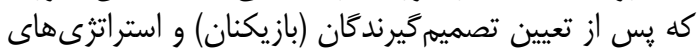

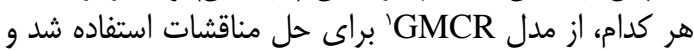

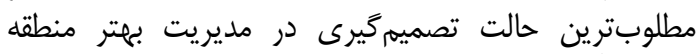

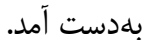

نظريه بازىها شاخهاى از عله رياضيات كاربردى است

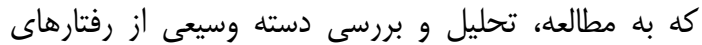

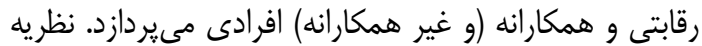

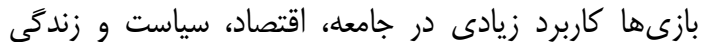
دارد (T). (广).

در نظريه بازىها به تعاملاتى كه بين تصميم دو طرف باري

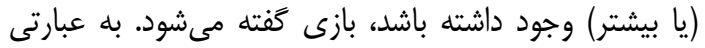

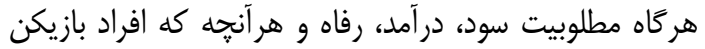

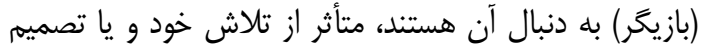

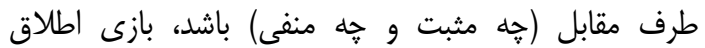

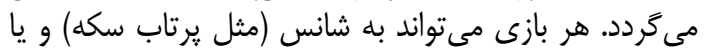

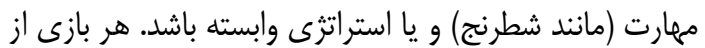

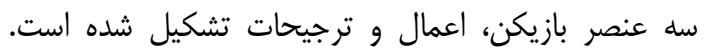

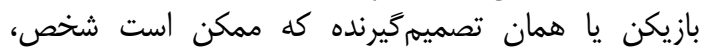

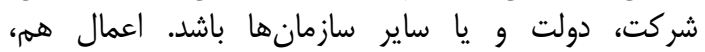

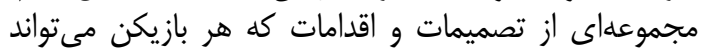

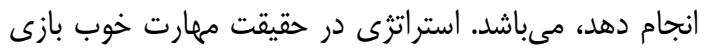

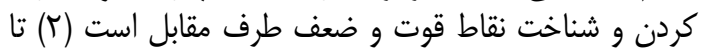

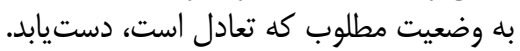

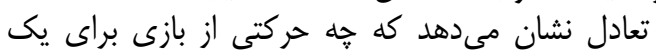

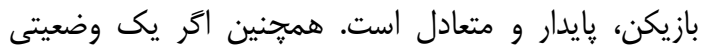

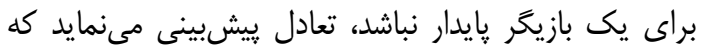

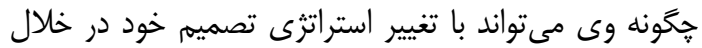

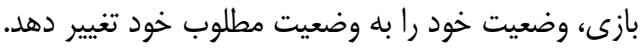

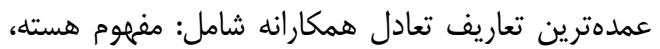

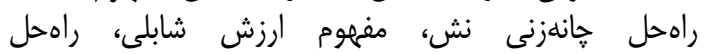

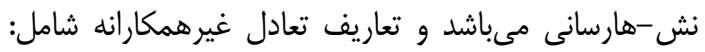

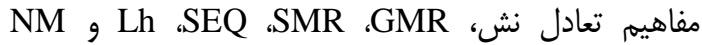
مىباشد (•) - (1).

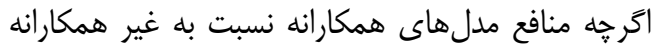

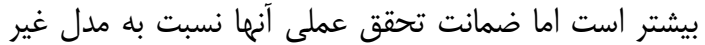

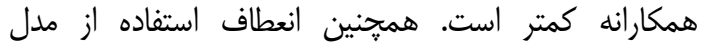

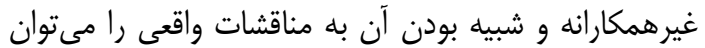

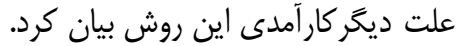

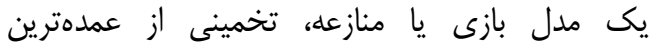
جنبههاى يك منازعه و سادهسازى آن تا حدى كازئ كه آسانتر

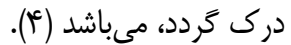

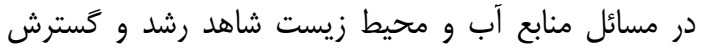

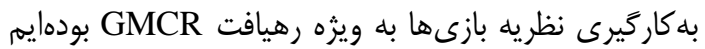

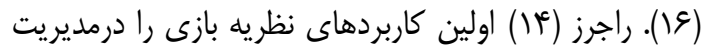

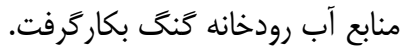

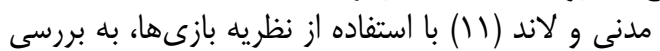

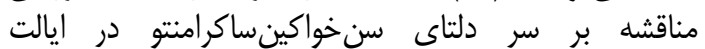

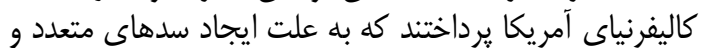

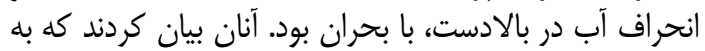

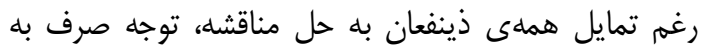

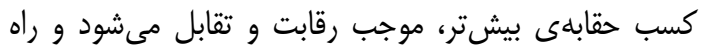

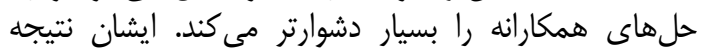
كرفتند كه هل منارانه راقشهى دلتا، بدون دخارت دخالت نهاد ارشد نيجل 


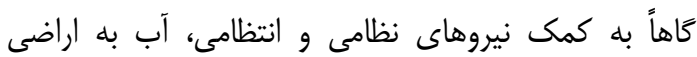

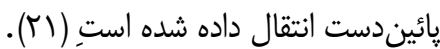

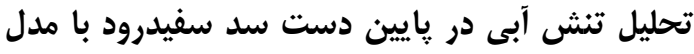

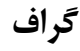

بلهمنظور بررسى تنش آبى پإييندست سفيدرود از ماز

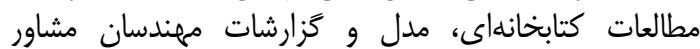

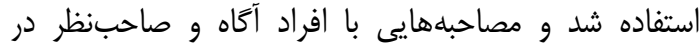

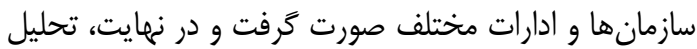

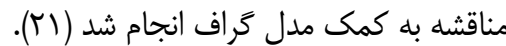

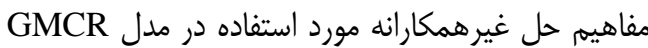

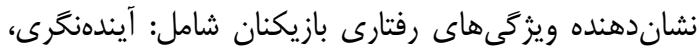

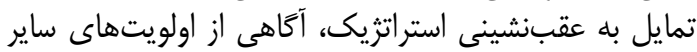

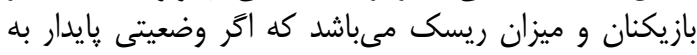

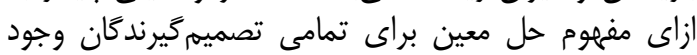

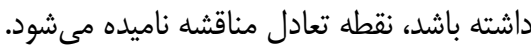

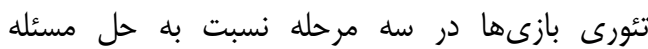

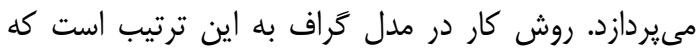

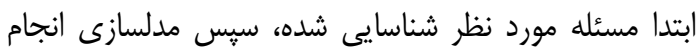

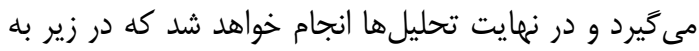

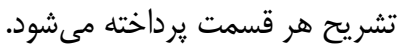

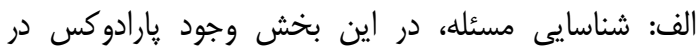

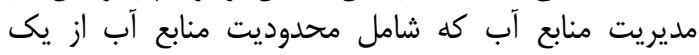

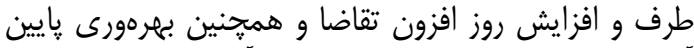

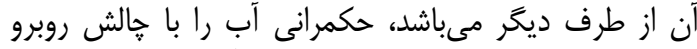

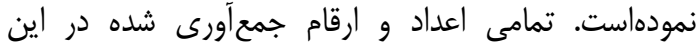

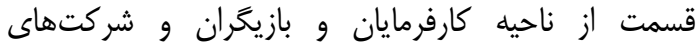
مهندسين مشاور و مصاحبه با مديران و كارفارئ كاناسان خبره

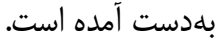

ب: مرحله مدلسازى، در اين مرحله هـ كار صورت مى مَيرد

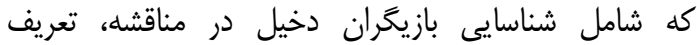

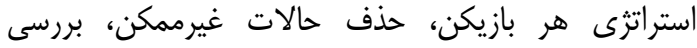

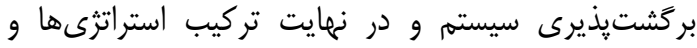
تعيين ييامدهاى ممكن مى بياشدي.

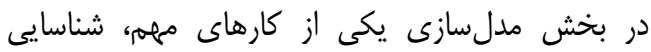

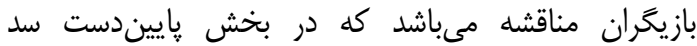

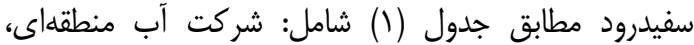

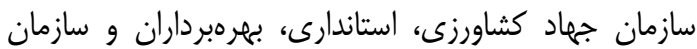

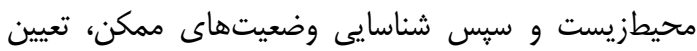
انتقال وضعيتهاى مجاز و بالاخره تعيين اولويتهاي مائ نسبى نعيى

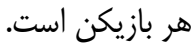

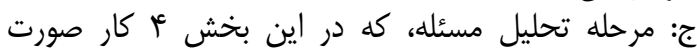

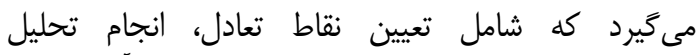

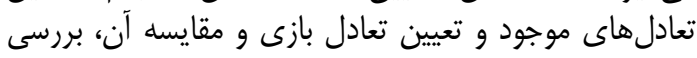
بهترين روش و تحليل حساسيت، بحث و و نتيجهذيرى

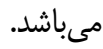

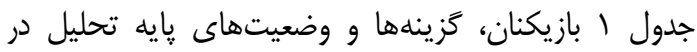
بخش ياييندست سد سفيدرود را نمايش مى دهد.
مواد و روشهاء

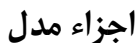

يك مدل منازعه از سه جزء جناء تشكيل يافته است:

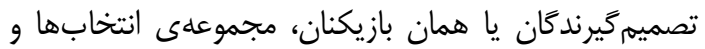

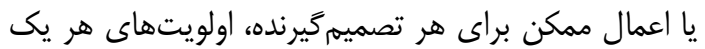

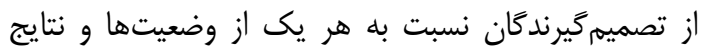

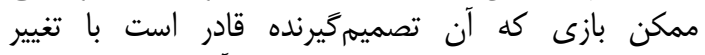

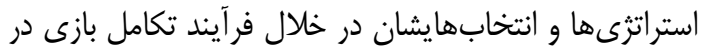

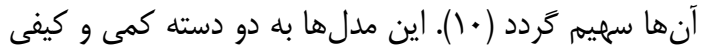

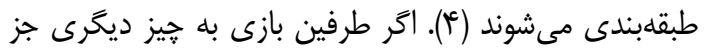

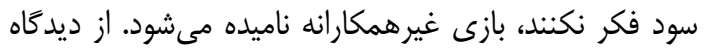

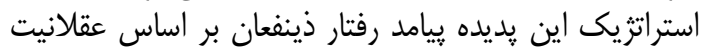

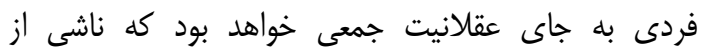

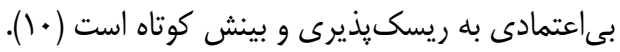

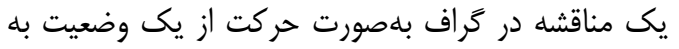

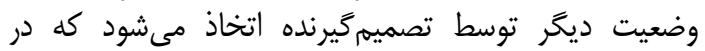

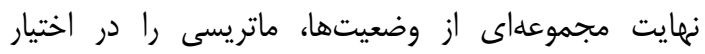

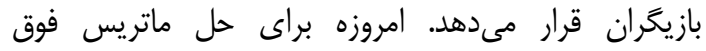

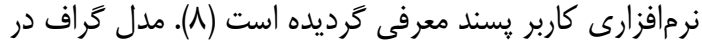

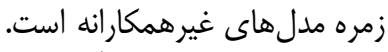

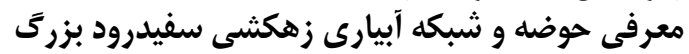

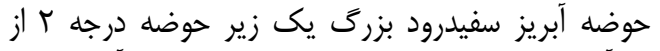

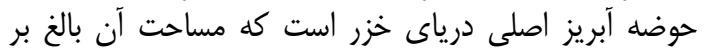

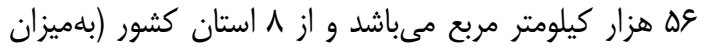

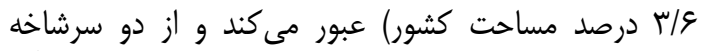

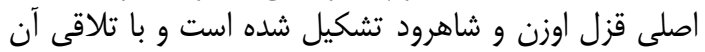

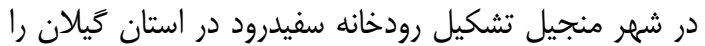

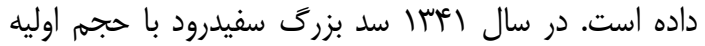
IV9D

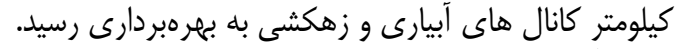

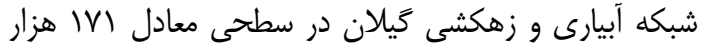

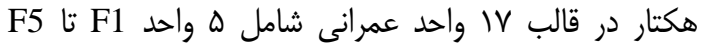

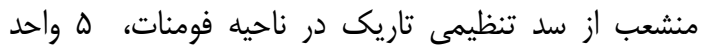

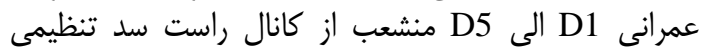

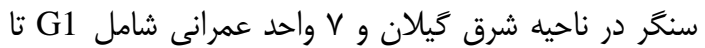

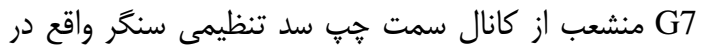

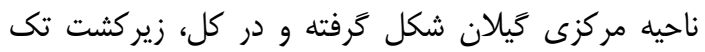

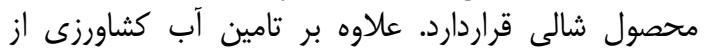

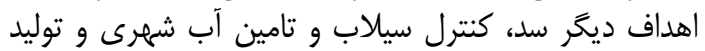

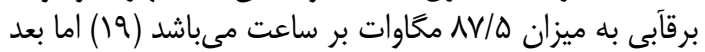

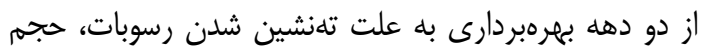

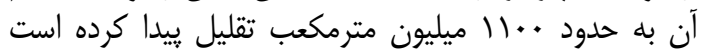

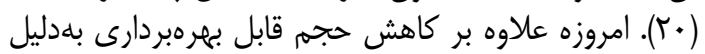

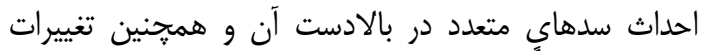

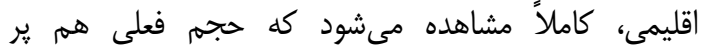

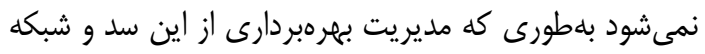
را دجار خالش نموده و خشكسالى هايى را به دنبال داشته كه آنه 
Table 1. Players, alternatives and base status of analysis of lower part of Sefidrud dam

\begin{tabular}{|c|c|}
\hline وضع بايه & 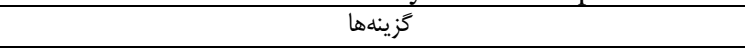 \\
\hline $\mathrm{Y}$ & توليد بيشتر محصولات كشاورزى در سطح وسيع تر \\
\hline $\mathrm{Y}$ & جراى زيرساختها (طرحهاى تجهيز و نوسازى اراضى، توسعه سامانههاى آبيارى نوين) \\
\hline $\mathrm{Y}$ & توزيع آب مورد نياز \\
\hline $\mathrm{N}$ & 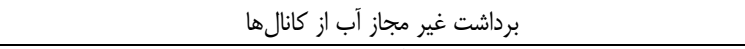 \\
\hline $\mathrm{N}$ & اجراى أبيارى نوبتى \\
\hline $\mathrm{Y}$ & توزيع عادلانه آب \\
\hline $\mathrm{Y}$ & اعمال قانون حقابه زيست محيطى \\
\hline
\end{tabular}

اولويت بازيكران

اولويت سازمان جهاد كثاورزى تيلان

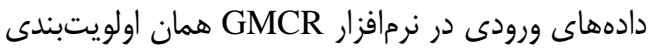

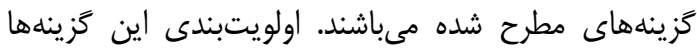

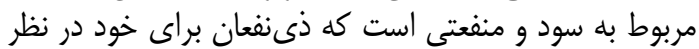

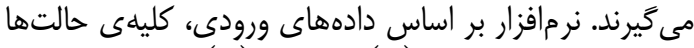

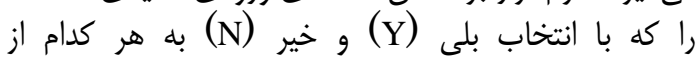
كزينهائ مطرح شده توسط بازيكنان نسبت داده مى شوده. ير برازش مى كند.

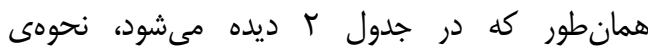

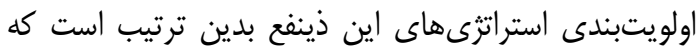

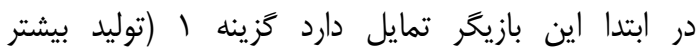

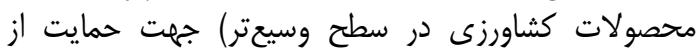

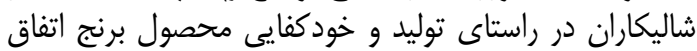

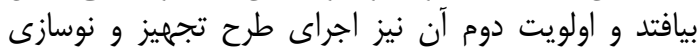

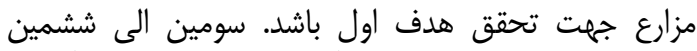
اولويت به ترتيب شاملا: توزيع آب مورد نياز و اجراى آبيارى

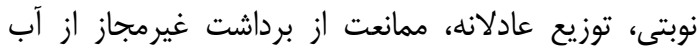

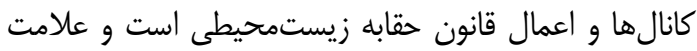
منفى در اولويت ينجهم بدان معنا است كه اين ذينفع تمايلى به رخداد اين كزينه ندارد.
بِّ إز انجام مطالعات مقدماتى و بررسى كلى شرايط بخش باييندست سل سفيدرود، تعارضات آبى موجود در اين

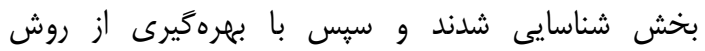
GMCR

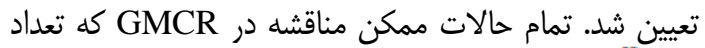

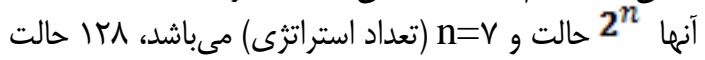

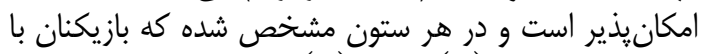

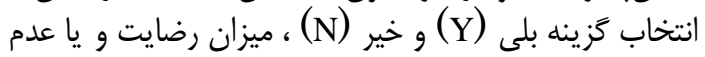
رضايت خود را به صورت كيفى از وضعيت موجود بيان

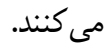
حذف وضعيتهاى ناممكن مناقشه

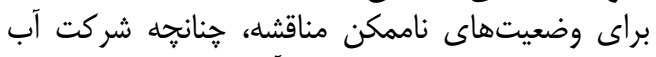

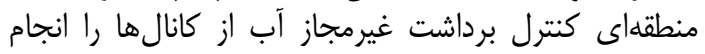

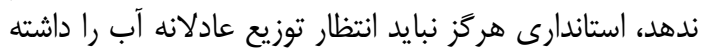

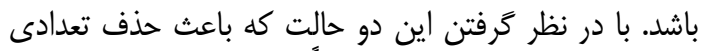

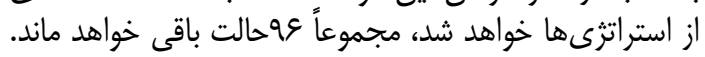
در بخش انتقال وضعيت مجاز تمام بازيكانان، بايد امكان

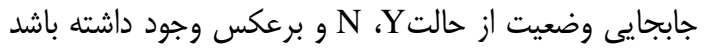

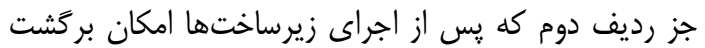
وجود ندارد.

جدول r- نحوهى اولويتبندى استراتزىهاى سازمان جهاد كشاورزى گيلان Table 2. Prioritization of strategies of the agricultural jihad organization of Guilan

\begin{tabular}{|c|c|c|}
\hline استراتزى ها (كزينه ها) & شماره گزينهها & نحوه اولويتبندى \\
\hline توليد بيشتر محصولات كشاورزى در سطح وسيعتر & 1 & 1 \\
\hline اجراى زيرساختها ( طرحهاى تجهيز و نوسازى اراضى ،توسعه سامانههاى آبيارى نوين) & r & r \\
\hline 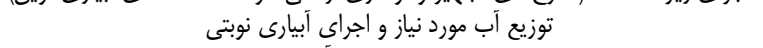 & $\Delta_{g}$ & r \\
\hline توزيع عادلانه آب & 8 & r \\
\hline 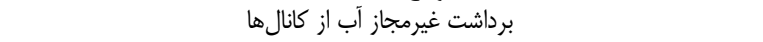 & $-t$ & $\Delta$ \\
\hline اعمال قانون حقابه زيست محيطى & $\checkmark$ & $\varepsilon$ \\
\hline
\end{tabular}

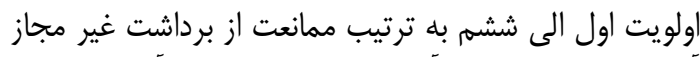

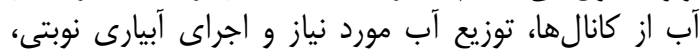
توليد بيشتر محصولات كشاورزى در سطح وسيعتر، اجراي آبراي

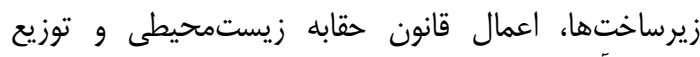

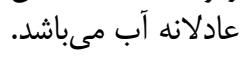

اولويت شركت آب منطقهاى كيلان

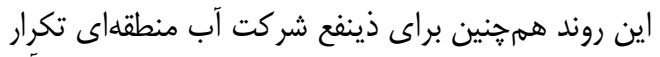

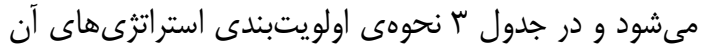

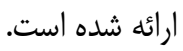


جدول س- نحوهى اولويتبندى استراتزىهاى شركت آب منطقهاى كَيلان Table 3. Prioritization of strategies of the regional water company of Guilan

\begin{tabular}{|c|c|c|}
\hline استراتزى ها (كزينهها) & شماره "زينها & نحوه اولويتبندى \\
\hline برداشت غيرمجاز آب از كانالها & -4 & 1 \\
\hline توزيع آب مورد نياز و اجراى آبيارى نوبتى & rاgه & r \\
\hline توليد بيشتر محصولات كشاورزى در سطح وسيعتر & 1 & r \\
\hline 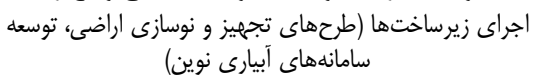 & $r$ & c \\
\hline اعمال قانون حقابه زيست محيطى & v & $\Delta$ \\
\hline توزيع عادلانه آب & \& & $\varepsilon$ \\
\hline
\end{tabular}

سطح وسيعتر، اجراى زيرساختها، عدم توزيع عادلانه و

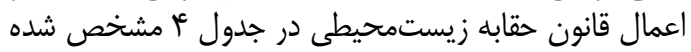

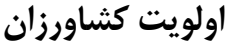

اولويت استراتزىهاى كشاورزان نيز بلترتيب توزيع آب آبان

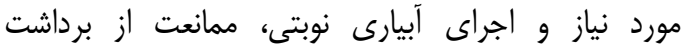
غيرمجاز آب از كانال، توليد بيشتر محصولات كشاورزى در

Table 4. Prioritization of strategies of the farmers in the lower part of the Sefidrud dam

جدول ع- نحوهى اولويتبندى استراتزىهاى كشاورزان ذينفع در بخش پاييندست سد سفيدرود

\begin{tabular}{|c|c|c|}
\hline استراتثى ها (كزينهها) & شماره كزينهها & نحوه اولويتبندى \\
\hline توزيع آب مورد نياز و اجراى آبيارى نوبتى & $-r_{g}-\Delta$ & 1 \\
\hline برداشت غيرمجاز آب از كانالها & r & r \\
\hline توليد بيشتر محصولات كشاورزى در سطح وسيعتر & 1 & $r$ \\
\hline 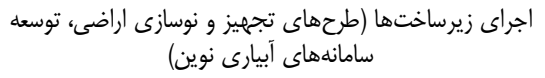 & $r$ & ${ }^{t}$ \\
\hline توزيع عادلانه آب & -9 & $\Delta$ \\
\hline اعمال قانون حقابه زيست محيطى & $-\gamma$ & 8 \\
\hline
\end{tabular}

اولويت استاندارى تَيلان

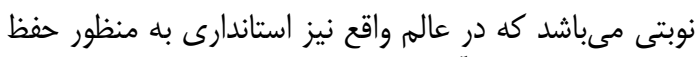

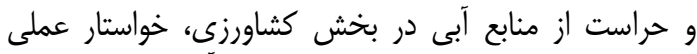

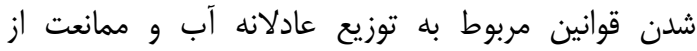

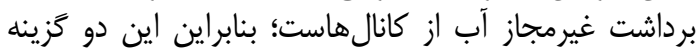
در اولين و دومين اولويتهاي ابيت اين سازمان قرارئ دارين دارد.

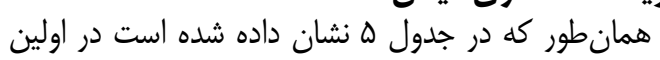

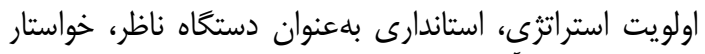

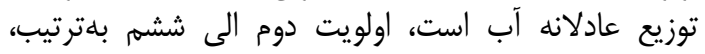

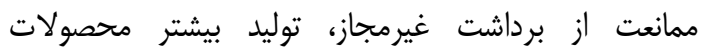

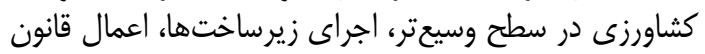
حقابه زيستمحيطى و توزيع آب مورد نياز و اجراى آبيارى إنى

جدول ه- نحوهى اولويتبندى استراتثىهاى استاندارى كيلان

Table 5. Prioritization of strategies of the governorate of Guilan

\begin{tabular}{|c|c|c|}
\hline نحوه اولويتبندى & استراتثىها (گزينهها) & شماره گزينهها \\
\hline r & $-r$ & برداشت غيرمجاز آب از كانال ها \\
\hline r & 1 & توليد بيشتر محصولات كشاورزى در سطح وسيعتر \\
\hline f & $r$ & اجراى زيرساختها (طرحهاى تجهيز و نوسازى اراضى، توسعه سامانهاى آبيارى نوين) \\
\hline$\Delta$ & v & اعمال قانون حقابه زيست محيطى \\
\hline
\end{tabular}

كشاورزى در سطح وسيعتر و در نهايت توزيع آب مورد نياز

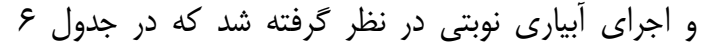
قابل مشاهده است.
اولويت سازمان محيط زيست تَيلان

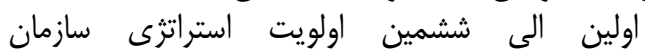

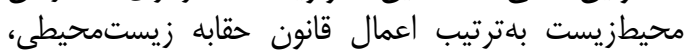

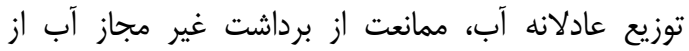
كانالها، اجراى زيرساختها، توليد بيشتر محصولات آنات 
Table 6. Prioritization of strategies of the environmental organization of Guilan

\begin{tabular}{|c|c|c|}
\hline نحوه اولويتبندى & 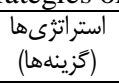 & شماره كزينها \\
\hline 1 & $\mathrm{~V}$ & اعمال قانون حقابه زيست محيطى \\
\hline r & 9 & توزيع عادلانه آب \\
\hline r & $-t^{2}$ & برداشت غيرمجاز آب از كانالها \\
\hline f & r & اجراى زيرساختها (طرحهاى تجهيز و نوسازى اراضى ،توسعه سامانههاى آبيارى نوين) \\
\hline$\Delta$ & 1 & توليد بيشتر محصولات كشاورزى در سطح وسيعتر \\
\hline \& & rاgه & توزيع آب مورد نياز و اجراى آبيارى نوبتى \\
\hline
\end{tabular}

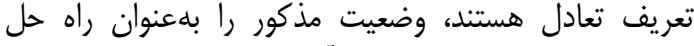

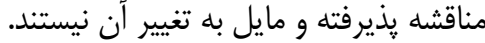

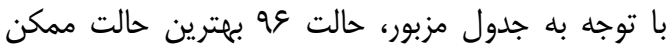

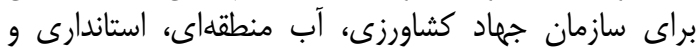

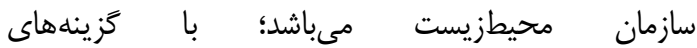
Y,Y,Y,N,Y,Y,Y

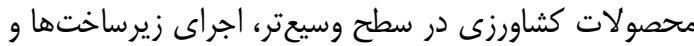

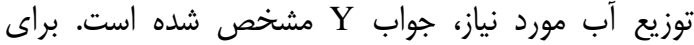

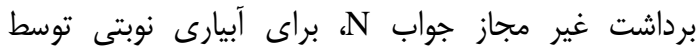

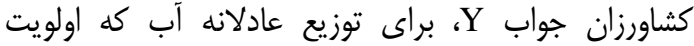

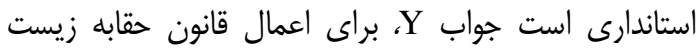

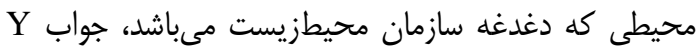

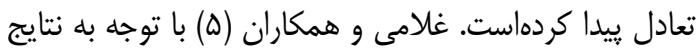

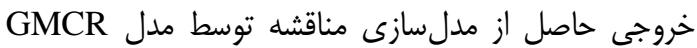

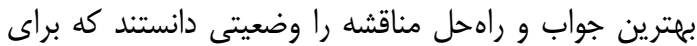

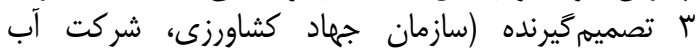

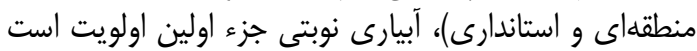

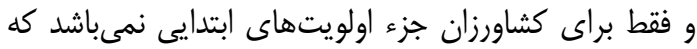

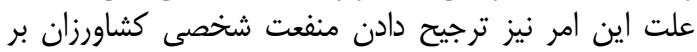
منفعت كل شبكه مىباشد.
تحليل مناقشه

يس از مدلسازى مناقشه بله كمك تعاريف تعادل

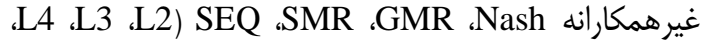
و Limited-Move (h=6: L10 L29 ،L8 ،L7 ،66 L5 Non-Myopic

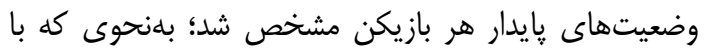

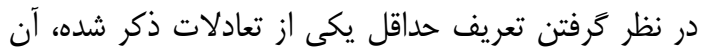

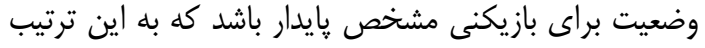

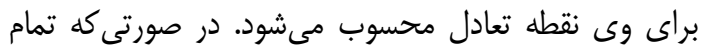

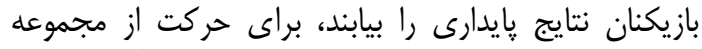

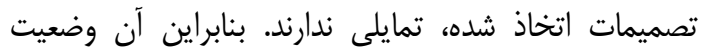

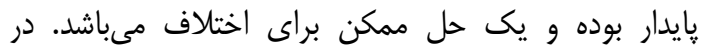

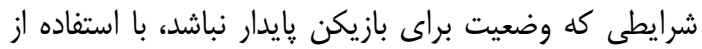

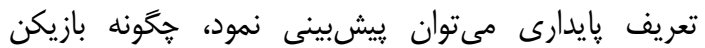

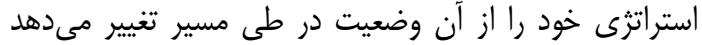

نقاط تعادل مناقثه

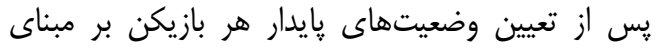
تعاريف تعادل، حال بايستى نقاط تعادل بازى رال را مشخص

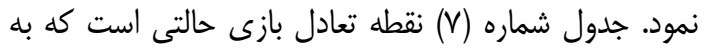

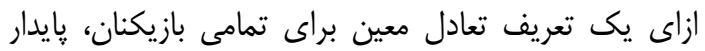

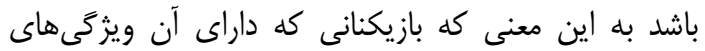

جدول V- نقاط تعادل مناقشه بخش پايين دست سد سفيدرود Table 7. Equiblirium points of the conflicts in the lower part of the Sefidrud dam

\begin{tabular}{|c|c|c|c|c|c|}
\hline \multirow{2}{*}{ تصميم كيرندكان } & \multirow[b]{2}{*}{ استراتزى } & \multicolumn{4}{|c|}{ نقاط تعادل } \\
\hline & & Af & $M$ & qr & १९ \\
\hline \multirow[b]{2}{*}{ 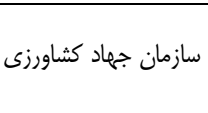 } & توليد بيشتر محصولات كشاورزى در سطح وسيع تر & $\mathrm{Y}$ & $\mathrm{Y}$ & $\mathrm{Y}$ & $\mathrm{Y}$ \\
\hline & 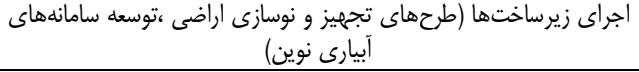 & $\mathrm{Y}$ & $\mathrm{Y}$ & $\mathrm{Y}$ & $\mathrm{Y}$ \\
\hline \multirow{2}{*}{ شركت آب منطقهاى } & توزيع أب مورد نياز & $\mathrm{N}$ & $\mathrm{Y}$ & $\mathrm{N}$ & $\mathrm{Y}$ \\
\hline & برداشت غيرمجاز آب از كانالها & $\mathrm{N}$ & $\mathrm{N}$ & $\mathrm{N}$ & $\mathrm{N}$ \\
\hline 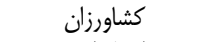 & اجراى أبيارى نوبتى & $\mathrm{N}$ & $\mathrm{N}$ & $\mathrm{Y}$ & $\mathrm{Y}$ \\
\hline استاندارى & توزيع عادلانه آب & $\mathrm{Y}$ & $\mathrm{Y}$ & $\mathrm{Y}$ & $\mathrm{Y}$ \\
\hline سازمان محيطزيست & اعمال قانون حقابه زيستمحيطى & $\mathrm{Y}$ & $\mathrm{Y}$ & $\mathrm{Y}$ & $\mathrm{Y}$ \\
\hline \multicolumn{2}{|r|}{ تعداد بإيدارى بر اساس تعاريف تعادل غيرهمكارانه } & 9 & 9 & $r$ & 9 \\
\hline
\end{tabular}

ميزان اولويت هر نقطه تعادل براى هر بازيكن بر اساس

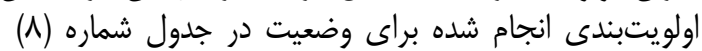
نشان داده شده است. 
جدول ^- ميزان اولويت و ارجحيت نقاط تعادل مناقشهى بخش ياييندست سد سفيدرود براى هر يك از تصميمگيرندگان Table 8. The priority and preference of the conflict points in the lower part of the Sefidrud dam for each of the

\begin{tabular}{|c|c|c|c|c|c|}
\hline \multirow{2}{*}{ تصميم گيرندكان } & \multirow{2}{*}{ استراتثى } & \multicolumn{4}{|c|}{ نقاط تعادل } \\
\hline & & Ne & $M$ & $9 T$ & 99 \\
\hline \multirow{2}{*}{ سازمان جهاد كشاورىى } & حمايت از كشاورز براى بهبود الخوى كشت و آبيارى & $\mathrm{Y}$ & $\mathrm{Y}$ & $\mathrm{Y}$ & $\mathrm{Y}$ \\
\hline & اجراى طرحهاى تجهيز و نوسازى اراضى شاليزارى & $\mathrm{Y}$ & $\mathrm{Y}$ & $\mathrm{Y}$ & $\mathrm{Y}$ \\
\hline \multirow{2}{*}{ شركت آب منطقه اى } & توزيع آب مورد نياز & $\mathrm{N}$ & $\mathrm{Y}$ & $\mathrm{N}$ & $\mathrm{Y}$ \\
\hline & برداشت غيرمجاز آب از كانالها & $\mathrm{N}$ & $\mathrm{N}$ & $\mathrm{N}$ & $\mathrm{N}$ \\
\hline 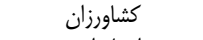 & اجراى آبيارى نوبتى & $\mathrm{N}$ & $\mathrm{N}$ & $\mathrm{Y}$ & $\mathrm{Y}$ \\
\hline استاندارى & توزيع عادلانه آب & $\mathrm{Y}$ & $\mathrm{Y}$ & $\mathrm{Y}$ & $\mathrm{Y}$ \\
\hline \multirow[t]{6}{*}{ سازمان محيط زيست } & جلوكيرى از عدم اعمال قانون حقابه زيست محيطى & $\mathrm{Y}$ & $\mathrm{Y}$ & $\mathrm{Y}$ & $\mathrm{Y}$ \\
\hline & اولويت حالت براى سازمان جهاد كشاورزى & $\wedge$ & 9 & v & 1 \\
\hline & أولويت حالت براى شركت آب منطقهاى & 11 & 19 & iv & 1 \\
\hline & اولويت حالت براى كشاورزان & ir & $\Delta \wedge$ & $\Delta q$ & 4. \\
\hline & اولويت حالت براى استاندارى & f & r & r & 1 \\
\hline & اولويت حالت براى سازمان محيط زيست & r & $r$ & f & 1 \\
\hline
\end{tabular}

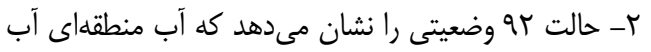

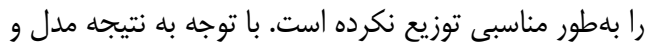

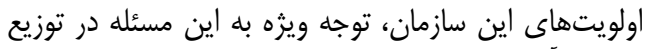
مناسب آب ميان بخشهاى إن ذينفع جهت كاهش ونه مناقشات،

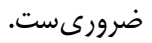

r- در حالت عو نيز كه مطلوبترين حالت مناقشه مىباشد

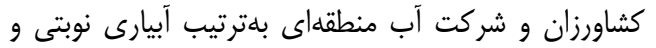

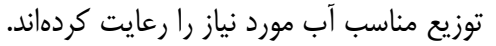

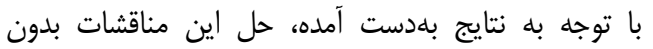

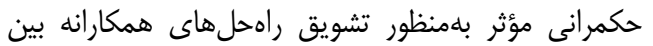

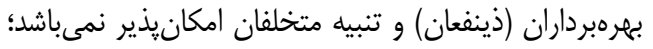

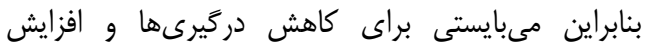

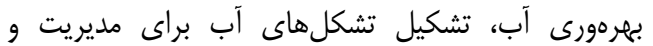

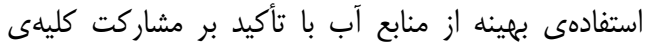

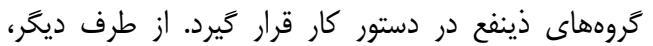

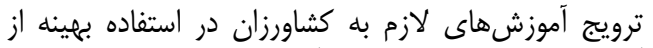

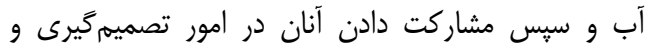

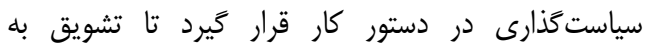

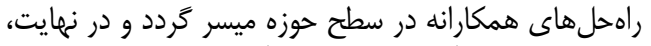

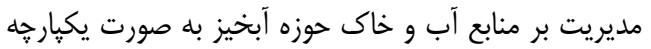

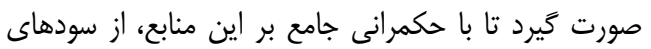

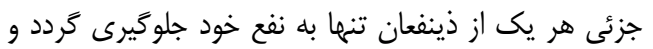

$$
\text { مكانيسم تنبيه متخلفان نيز اجرايى شود. }
$$

همانطور كه ملاحظه مى شود در نقاط تعادل، أ وضعيت

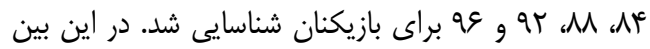

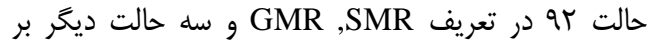

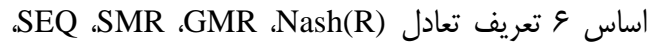

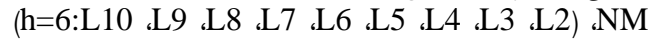

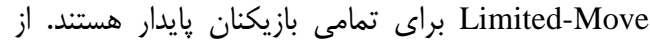

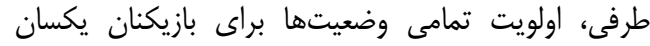

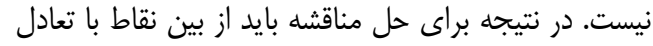

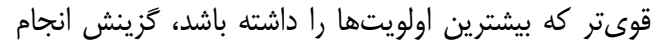
شود.

در اين يثوهش مناقشه در حوزه آبخيز سد سفيدرود

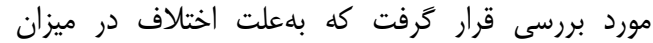

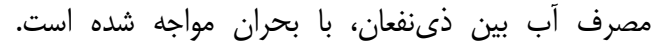

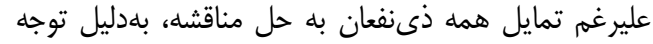

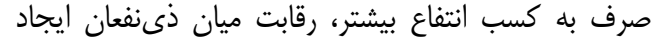

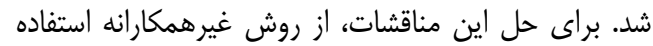

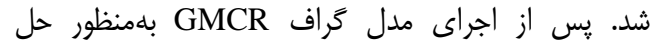
مناقشات، نتايج زير حاصل شر شد

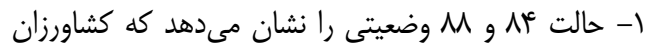

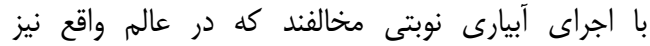

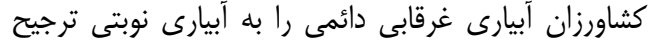

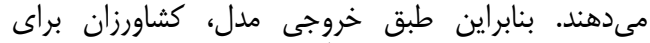

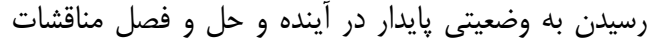
موجود، بايستى اجراى آبيارى نوبتى را رعايت كنند. 
1. Alizadeh, M.R., M.R. Nikoo and Gh.R. Rakhshandehrou. 2016. Developing an optimal groundwater allocation model considering stakeholder interactions; application of fallback bargaining models. Iran Water Resources Research, 11(3): 43-56 (In Persian).

2. Abdoly, Gh. 2011. Game theory and its applications. Iranian Students Booking Agency, 454 pp (In Persian).

3. Dinar, A. 2006. Water Allocation Strategies for the Kat Basin in South Africa: Comparing Negotiation Tools and Game Theory Models. World Bank Policy Research Working Paper, 4083pp.

4. Fang, L., K. Hipel and M. Kilgour. 1993. Interactive Decision Making: The Graph Model for Conflict Resolution, Wiley, New York.

5. Golami, M., A. Shahnazari, M. Mortezapour and M. Shahnourian. 2016. Conflict resolution of Sefidrud Irrigation and Drainage Network with Game Theory. Journal of Iran Water Resources Research, (In press).

6. Hardin, G. 1968. The tragedy of the commons. Science, 162: 1243-1248.

7. Hipel, K.W., D.M. Kilgour, L. Fang and M. Haight.1993. Environmental conflict resolution using the graph model. International conference on systems, Man and Cybernetics, systems engineering in the service of humans, Conference proceeding.

8. Kassab, M. and K.W. Hipel. 2006. Conflich Resolution in Construction Disputes Using the Graph model. Journal of Construction Engi. And Manag, 132(10): 1043-1052.

9. Madani, K. 2010. Game theory and water resources. Journal of Hydrology, 31(3-4): 225-238.

10. Madani, K. and K.W. Hipel. 2011. Non-cooperative stability definitions for strategic analysis of generic water resources conflicts. Water Resource Manage, 25: 1949-1977.

11. Madani, K. and J. Lund. 2011. A Monte-Carlo game theoretic approach for multi-criteria decision making under uncertainty. Advances in Water Resources, 34(5): 607-616.

12. Madani, K. and M.A. Marino. 2009. System Dynamic Analysis for managing Iran Zayandeh-Rud river Basin. Water Resourses Manage, 23: 2163-2187.

13. Raquel, S., S. Ferenc, Jr.C. Emery and R. Abraham. 2007. Application of game theory for a groundwater conflict in Mexico. Journal of Environmental Management, 84: 560-571.

14. Rogers, P. 1969. A game theory approach to the problems of international river basin. Water Resources Research, 5(4): 749-760.

15. Rogers, P. and A.W. Holl. 2003. Effective water governance Stockholm. Golden Water Partnership, $1-7$.

16. Safaee A, B. Malek Mohammadi. 2014. Game theoretic insights for sustainable common poll water resources governance (case study: Lake Urmia water conflict).Journal of Enviromental Studies, 40(1): 121-138 (In Persian).

17. Salazar, R. 2007. Application of game theory for a groundwater conflict in Mexico. Journal of environmental Management, 560-571.

18. Sensarma, S.R. and N. Okada. 2006. The process of conflict resolution: A case study ofichinose disaster management conflict, tottori prefecture. Japan Annual of Disas. Pre.Res. INS, Kyotouniv.

19. Sougrah Consulting Engineers. 1962. Report on Development of water resources of the province of Guilan. Guilan Regional Water Authority (In Persian).

20. Water Research Institute. 2010. Report on Studies on the sedimentation process in dam's reservoirs and the provision of a mathematical model for predicting the sedimentation pattern along with the case study of Sefidrood Dam. Guilan Regional Water Authority (In Persian).

21. Water Research Institute. 2011. Report on Integrated studies of water resources planning in Ghezloosen-Sefidrud watershed. Guilan Regional Water Authority (In Persian).

22. Zarezadeh, M., S. Morid, F. Fatemi and K. Madani. 2016. The strategic cooperation between Iran and Afghanistan in Helmand basin to allocate more water to environment and control opium cultivation using game theory approach. Iran Water Resources Research, 12(3): 12-21 (In Persian). 


\title{
Water Governance in the Sefidrud Basin using the Theory of Games Approach
}

\author{
Mohammad Reza Mortezapour ${ }^{1}$, Ali Shahnazari ${ }^{2}$ and Mohammad Reza Khaledian ${ }^{3}$ \\ 1- P.hD. Student, of Water Engineering, Sari Agricultural Sciences and Natural Resources University \\ 2- Professor, of Water Engineering, Sari Agricultural Sciences and Natural Resources University \\ (Corresponding author: aliponh@yahoo.com) \\ 3- Associate Professor, Water Engineering Dept., Faculty of Agricultural Sciences, University of Guilan, \\ and Department of Water Engineering and Environment, Caspian Sea Basin Research Center \\ Received: July 26, 2017 \\ Accepted: August 30, 2017
}

\begin{abstract}
Water resources management in the country has been confronted with conflicts over the last years due to increasing demand on one hand and decreasing renewable water per capita on the other hand. The game theory is one of the scientific methods for resolving conflicts in management. The purpose of this study is to investigate and provide a solution to the conflict resolution of downstream part of Sefidrud dam using game theory. For modeling and analysis of the conflict, Graph Model for Conflict Resolution (GMCR) was used. After determining players (Agricultural Jihad Organization, Regional Water Company, Farmers, Governorate and Environmental Organization) and options and inserting them into the model, 128 states were created in this conflict. It uses non-cooperative solution concepts. With regard to prioritize strategies by decision-makers, 4 situations were identified as equilibrium points. After the final analysis of the software the most favorable state in the conflict between the points of equilibrium was the state of 96 that the farmers and the regional water company, respectively, have observed alternative irrigation and proper distribution of water required According to the results, solving these conflicts without effective governance in the large Sefidrud watershed is not possible due to the cooperation between the exploiters and the punishment of the offenders.
\end{abstract}

Keywords: Games Theory, Conflict, Equilibrium Points, GMCR Model, Sefidrud Basin 